\title{
A writer's guide to education scholarship: Quantitative methodologies for medical education research (part 1)
}

\author{
Brent Thoma, MD, MA, MSc*; Paola Camorlinga, MD ${ }^{\dagger}$; Teresa M. Chan, HBSc, BEd, MD, MHPE ; \\ Andrew Koch Hall, MD, MMEd ${ }^{\delta}$; Aleisha Murnaghan, BSc, MD, MHPEף; Jonathan Sherbino, MD, MEd ${ }^{\ddagger}$
}

\section{ABSTRACT}

Background: Quantitative research is one of the many research methods used to help educators advance their understanding of questions in medical education. However, little research has been done on how to succeed in publishing in this area.

Objective: We conducted a scoping review to identify key recommendations and reporting guidelines for quantitative educational research and scholarship.

Methods: Medline, ERIC, and Google Scholar were searched for English-language articles published between 2006 and January 2016 using the search terms, "research design," "quantitative," "quantitative methods," and "medical education." A hand search was completed for additional references during the full-text review. Titles/abstracts were reviewed by two authors (BT, PC) and included if they focused on quantitative research in medical education and outlined reporting guidelines, or provided recommendations on conducting quantitative research. One hundred articles were reviewed in parallel with the first 30 used for calibration and the subsequent 70 to calculate Cohen's kappa coefficient. Two reviewers (BT, PC) conducted a full text review and extracted recommendations and reporting guidelines. A simple thematic analysis summarized the extracted recommendations. Results: Sixty-one articles were reviewed in full, and 157 recommendations were extracted. The thematic analysis identified 86 items, 14 categories, and 3 themes. Fourteen quality evaluation tools and reporting guidelines were found. Discussion: This paper provides guidance for junior researchers in the form of key quality markers and reporting guidelines. We hope that quantitative researchers in medical education will be informed by the results and that further work will be done to refine the list of recommendations.

\section{RÉSUMÉ}

Introduction: La recherche quantitative est I'une des nombreuses méthodes de recherche utilisées pour aider les éducateurs à mieux comprendre les questions en matière d'enseignement de la médecine. Toutefois, peu de recherche a été faite sur la manière de s'y prendre pour réussir à publier des articles dans le domaine. Aussi avons-nous mené un examen de la portée afin de relever les principales recommandations et les grandes lignes directrices sur l'établissement de rapports en ce qui concerne la recherche quantitative en enseignement et la production de travaux scientifiques.

Méthodes: Les auteurs ont compulsé les bases de données Medline, ERIC et Google Scholar à la recherche d'articles publiés en anglais, entre 2006 et janvier 2016 à l'aide des termes research design, quantitative, quantitative methods et medical education. Une recherche manuelle de références complémentaires a aussi été effectuée durant l'examen des textes en version intégrale. Les titres et les résumés analytiques ont fait I'objet d'un examen par deux auteurs (BT, PC), et les articles ont été retenus s'ils portaient principalement sur la recherche quantitative en enseignement de la médecine et s'ils présentaient des lignes directrices sur l'établissement de rapports ou s'ils faisaient état de recommandations sur la manière d'effectuer de la recherche quantitative. Cent articles ont été examinés en parallèle, dont les 30 premiers aux fins d'étalonnage, et les 70 autres, aux fins du calcul de la valeur kappa de Cohen. Deux examinateurs (BT, PC) ont procédé à l'examen des textes en version intégrale, puis en ont dégagé les recommandations et les lignes directrices sur l'établissement de rapports. C'est à l'aide d'une simple analyse thématique que les recommandations ont ensuite été résumées.

Résultats: Les auteurs ont procédé à l'examen de 61 articles en version intégrale, et dégagé 157 recommandations. L'analyse thématique a permis de diviser la matière en 3 thèmes, en 14 catégories et en 86 éléments. II s'est dégagé finalement de la recherche 14 outils d'évaluation de la qualité et lignes directrices sur l'établissement de rapports.

Discussion: L'article offre aux jeunes chercheurs un guide présentant les principaux marqueurs de qualité et les grandes lignes directrices sur l'établissement de rapports. Nous espérons que les résultats obtenus sauront guider les futurs

From the *Department of Emergency Medicine, University of Saskatchewan, Saskatoon, SK; †Department of Emergency Medicine, University of British Columbia, Vancouver, BC; ¥Division of Emergency Medicine, Department of Medicine, McMaster University, Hamilton, ON; §Department of Emergency Medicine, Queen's University, Kingston, ON; and IDepartment of Emergency Medicine, University of Ottawa, Ottawa, ON.

Correspondence to: Dr. Brent Thoma, Room 2646, Box 16, 103 Hospital Drive, Saskatoon, SK, S7N 0W8; Email: brent.thoma@usask.ca 
spécialistes de la recherche quantitative en enseignement de la médecine et que d'autres travaux de recherche seront entrepris afin d'étoffer la liste des recommandations.
Keywords: academic writing, education scholarship, publishing, quantitative research

\section{INTRODUCTION}

In 2013 the Canadian Association of Emergency Physicians (CAEP) conducted an inaugural academic symposium to develop a list of recommendations to promote educational scholarship among emergency physicians in Canada. ${ }^{1-3}$ The resulting manuscripts emphasized the importance of educational scholarship among emergency physicians in Canada and outlined the systemic and institutional supports necessary to develop clinician educators. Subsequently, this was identified as an area of leadership for emergency physicians. ${ }^{4,5}$ Despite this success, it is challenging to begin conducting research in medical education.

Most residents and physicians in emergency medicine have familiarity with the critical appraisal of quantitative diagnostic and therapeutic trials. However, translating this familiarity into research success remains challenging. ${ }^{6}$ This is especially true in medical education, where biomedical methodologies are often proposed to study questions that are more appropriately investigated using techniques developed in the social sciences. ${ }^{7}$ The perception that medical education research is "easy" relative to clinical research also persists, ${ }^{7}$ despite the availability of numerous masters and $\mathrm{PhD}$ level programs focused on preparing trainees to conduct rigorous medical education research.

Herein, as part of a series of writer's guides aimed at residents and junior scholars, we describe a scoping review $^{8}$ of the literature that outlines a list of recommendations for conducting and publishing quantitative educational research. In addition, we present a list of guidelines that establish the reporting and writing standards relevant to this field. We hope that this writer's guide will aid junior investigators as they conduct quantitative research in medical education.

\section{METHODS}

\section{Search methodology}

The authors conducted a focused literature review of three databases. An initial search using the MEDLINE database was restricted to English-language articles published from 2006 through January 2016 using “and/or" combinations of the following search terms: "research design," "quantitative," "quantitative methods," and "medical education." A second search using ERIC database was performed of English language articles published from 2006 through January 2016 using "and/or" combinations of the following search terms: "research design," "quantitative," "quantitative methods," and "medical education." A final search was conducted using Google Scholar, which was limited to English-language papers from 2006-2016 using the keywords "medical education" and "quantitative research." These articles were amalgamated in Mendeley, and duplicates were removed.

\section{Inclusion criteria}

Articles focused on quantitative research in medical education that outlined reporting guidelines, discussed the evaluation of quality in quantitative research, or provided advice on conducting quantitative research. Articles that focused on other forms of education scholarship, mixed methodologies, or did not address any of the study questions were excluded.

\section{Article review}

The results of the literature search were uploaded into Mendeley for analysis. Two authors (BT, PC) developed and performed the literature search and conducted the title and abstract review. The first 30 articles were reviewed in parallel to calibrate the reviewers. The subsequent 70 articles were reviewed separately, but in parallel. A kappa value was calculated to quantify interrater reliability. The remaining articles were then divided between the two authors (BT, PC) and reviewed by a single reviewer. A hand search of the reference lists of the included articles was conducted to identify those that were not found in the literature search.

A full text review of the included articles was conducted by two authors (BT, PC) with disagreements resolved through a discussion resulting in consensus. During the full text review, any quality evaluation criteria or reporting guidelines mentioned in the papers were abstracted along with recommendations for the conduct of quantitative medical education research. 


\section{Analysis}

During the full text review, a list of quality markers was developed by two reviewers (BT, PC) by extracting recommendations mentioned in text, figures, charts, diagrams, pictures, or tables. These recommendations were annotated and organized by article from which they were extracted. Two authors (BT, PC) performed a simple thematic analysis refining and aggregating the recommendations into a final common list. Items deemed alike were amalgamated into a single descriptive statement (Table 1). Simultaneously, during the full text review, reporting guidelines and quality assessment tools that were relevant to quantitative research and were mentioned in the text, figures, charts, diagrams, pictures, or tables were extracted and compiled.

\section{RESULTS}

\section{Scoping review}

The results of the literature review are outlined in Figure 1. The database search identified 356 articles (270 from Medline and 88 from ERIC with 2

\begin{tabular}{|c|c|}
\hline Category & Advice for quantitative research \\
\hline \multicolumn{2}{|l|}{ Study design } \\
\hline Standards & $\begin{array}{l}\text { Use Glassick's six standards }{ }^{9} \text { to assess the quality of scholarly activities: clear goals, demonstrate adequate preparation, employ appropriate } \\
\text { methods, you need outstanding results, communicate your results effectively and transparently, demonstrate reflective critique. }\end{array}$ \\
\hline \multirow[t]{5}{*}{ Literature review } & Conduct a literature review to define the research question and ensure that it has not already been answered. \\
\hline & Use the literature review to determine what works and does not work in your area of research. \\
\hline & Conduct a thorough literature review of both the medical literature and relevant publications from other disciplines. \\
\hline & Create an annotated bibliography during the literature review that includes notes about the relevance of the publication to the research problem. \\
\hline & Use a reference librarian to identify relevant search engines and journals for the literature search. \\
\hline \multirow[t]{10}{*}{ Question } & Clearly define a research question before selecting the most appropriate method to answer it. \\
\hline & Ensure that the research question is important (addresses gaps in knowledge base or clarifies educational processes). \\
\hline & Ensure that the research question is novel (expands on what is known or brings the voice of new individuals or population). \\
\hline & Refine the study question by writing a problem statement that describes the overall context of the study. \\
\hline & Identify a research question that is important to you. \\
\hline & Incorporate a conceptual framework into your research question. \\
\hline & Refine the study question using the FINER (feasible, interesting, novel, ethical, relevant) mnemonic. \\
\hline & Develop a structured research question using the PICOT (participants, intervention, control, outcome, time) format. \\
\hline & Higher level outcomes should be prioritized for research questions and study aims. \\
\hline & Consider conceptual and theoretical frameworks when formulating the research question. \\
\hline \multirow[t]{20}{*}{ Methods } & Increase generalizability by contributing to multidisciplinary, multi-institutional studies, and research networks. \\
\hline & Increase ecological generalizability by replicating studies in other contexts. \\
\hline & Increase population generalizability by using random or stratified sampling techniques. \\
\hline & $\begin{array}{l}\text { Adhere to generally accepted ethical standards (obtain informed consent, ensure voluntary participation, maintain confidentiality, and } \\
\text { receive ethical approval). }\end{array}$ \\
\hline & Consider the perspective of stakeholders (students, minorities, university, government, etc.) in the study design. \\
\hline & Obtain funding to allow for a more rigorous study design. \\
\hline & $\begin{array}{l}\text { Be realistic in the logistics of implementation, the feasibility of outcome assessment, the number of participants, and the budgeting of } \\
\text { time/money/other resources. }\end{array}$ \\
\hline & Adapt surrogate end points from clinical research guidelines for use in medical education research. \\
\hline & Include elements listed in guidelines such as the STROBE, CONSORT, and TREND statements in the study design. \\
\hline & Consider when to use and NOT use pretests in education research, to ensure that the testing itself does not impact the outcome. \\
\hline & Compare the studied educational intervention to a control group that receives a different intervention (rather than a non-intervention). \\
\hline & Ensure that differences between two interventions are focused, explicitly defined, and replicable. \\
\hline & Do not cue participants to the "new" approach being studied. \\
\hline & Use blinded assessors/coders for data collection. \\
\hline & When possible, randomize participants to each intervention. \\
\hline & Use representative sampling procedures. \\
\hline & Conduct a power analysis to determine the sample size needed for sufficient statistical power calculation. \\
\hline & Collaborate or consult a biostatistician in the planning stages of the study. \\
\hline & Emphasize confidence interval $(\mathrm{Cl})$ and effect sizes rather than $p$ values only. \\
\hline & $\begin{array}{l}\text { Avoid quasi-experimental study designs; true experimental study designs provide the strongest evidence of causality and minimize threats } \\
\text { to internal validity. }\end{array}$ \\
\hline
\end{tabular}


Thoma et al

Table 1. (Continued)

\begin{tabular}{|c|c|}
\hline Category & Advice for quantitative research \\
\hline \multirow{14}{*}{ Outcomes } & Consider an appropriate conceptual framework when selecting and describing the study design. \\
\hline & Avoid losing participants to follow up as much as possible. \\
\hline & Outcome measures should balance feasibility, meaningfulness, and advance outcome research in medical education. \\
\hline & $\begin{array}{l}\text { Consider cost-value (i.e., tutor time, equipment cost) and resources (administration support, money, willing participants) in resea } \\
\text { with regards to location (multi-centre trials) and ease of extrapolation. }\end{array}$ \\
\hline & $\begin{array}{l}\text { First, identify the broad class of outcomes (i.e., knowledge, skill, or behavior) and different measures available for each, followe } \\
\text { selecting the specific instrument to match the study goal (i.e., studies designed to improve skills should measure skills). }\end{array}$ \\
\hline & $\begin{array}{l}\text { Make the distinction between skills, behaviors, and patient effects when discussing patient-related outcomes of health professi } \\
\text { education and proceed in a stepwise fashion as you test educational interventions. }\end{array}$ \\
\hline & Select patient outcomes resulting in engagement of patients and the whole health care team. \\
\hline & Interventions should be based on theory or evidence. \\
\hline & $\begin{array}{l}\text { Achieve high external validity by repeating your experiment in different settings/populations and using international instruments } \\
\text { educational outcomes. }\end{array}$ \\
\hline & Attempt to limit threats to study validity (selection bias, instrument problems, implementation bias) in RCT and non-RCTs. \\
\hline & Verify predicted relationships between dependent and independent variables (construct validation). \\
\hline & Studies should gather and report validity evidence at the beginning stages of study design. \\
\hline & Reporting validity evidence and clinically relevant outcomes is associated with a manuscripts acceptance for publication. \\
\hline & $\begin{array}{l}\text { Consider the TAPUPAS (transparency, accuracy, purposivity, utility, propriety, accessibility, specificity) model when designing a } \\
\text { high-quality study. }\end{array}$ \\
\hline
\end{tabular}

Writing

Reduce barriers to starting writing by spontaneously and uncritically drafting the easiest parts of the manuscript.

Learn the anatomy of an educational research paper.

Problem statement Explain the importance or significance of the topic of study by highlighting gaps of understanding in the literature.

Conceptual Employ a strong conceptual framework to situate the research within an appropriate theoretical context.

framework Outline the topic and question within the related literature.

Methods $\quad$ Explain the study design in enough depth for replication.

Clearly define the population of interest and the inclusion and exclusion criteria of participants.

Clearly describe the educational context of the intervention.

Clearly describe the intervention and control groups.

Clearly describe the intervention in each of the study groups.

Clearly outline the anticipated effect of the intervention and how it will be observed.

Include statements about informed consent and institutional ethical approval.

Report all required elements outlined by relevant reporting guidelines.

Discussion Critically evaluate threats to the study's validity and rule out as many as possible using the literature.

Reflectively integrate the findings of the study with outside work without overstating study findings or understanding the work of others.

Discuss the results in relation to the strengths and weaknesses of the methodology.

Specifically outline future avenues for study and potential improvements of the methodology.

Provide a rich discussion of bias that includes the exploration of alternatives to the original hypotheses.

Editing Ensure that the language used is clear and unambiguous.

Use accepted or prescribed headings.

Ensure that the information presented in the tables and abstract is consistent with the text of the manuscript.

Do not delay submission of the study in an effort to make it perfect.

Have an experienced reviewer provide feedback on the manuscript prior to submission.

Accountability Cite all relevant articles.

Ensure that each cited comment is an accurate representation of the reference.

Safeguard all original data for accountability purposes.

Provide information on non-participants and participants who were lost to follow-up.

Explain critical methodological decisions, particularly when decisions lead to unusual or suboptimal methods.

Submission

Journal selection Ensure that the journal selected for submission publishes the type of paper that is being submitted.

Ensure that the manuscript meets the style and submission requirements of the selected journal.

Choose a journal that serves your target audience.

Revision

Try to balance conflicting reviewer recommendations.

Make suggested changes whenever reasonable and possible.

Provide well-reasoned responses to every major recommendation.

Communication Communicate with the journal's editorial staff when needed prior to formal submission to ascertain its interest in a particular paper. 


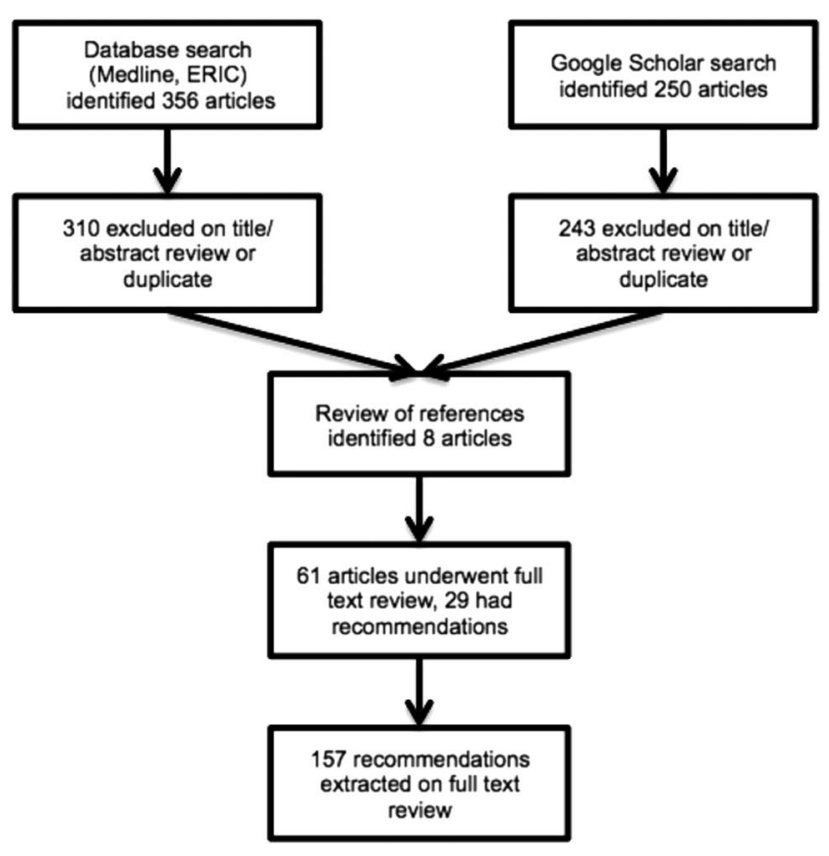

Figure 1. Flow diagram for systematic review.

duplicates), of which 46 were included on title/abstract review. The Google Scholar search conducted on January 18, 2016 returned 895,000 results. Of the 250 which were reviewed, 7 were included on title/abstract review. An additional 8 articles were included from a review of the references of the included studies.

The title/abstract review of articles 31 to 100 resulted in concordance on $97.1 \%(68 / 70)$ of the items with a kappa of 0.935 (95\% CI=0.847-1.0). The full text review excluded an additional 32 articles; 157 recommendations were extracted from the remaining 29 articles.

\section{Thematic analysis}

The simple thematic analysis of the recommendations for quantitative medical education research resulted in 3 themes (study design, writing, and submission), 14 categories, and 86 items (see Table 1).

\section{Quality evaluation tools and reporting guidelines}

Table 2 outlines the fourteen quality evaluation tools and reporting guidelines that were found during the full text review, which were applicable to quantitative medical education research.

\section{DISCUSSION}

Our scoping review ${ }^{8}$ identified 86 recommendations for conducting and 14 tools/guidelines for reporting highquality medical education research using quantitative methods. The recommendations found in the literature were congruent; however, their usefulness will be limited by the high number of items that were found. Although the qualitative analysis decreased the gross number of recommendations substantively, 86 may still be too many to consider. Regardless, we believe that reporting the complete list will be helpful to both inform future research and allow junior researchers to identify those items most pertinent to them. Moving forward, we will aim to triage the recommendations to determine which are the most important so that those can be focused on. Multiple methods of achieving consensus among diverse populations have been proposed and could be applied to identify the most important recommendations. ${ }^{23}$

A significant number of quality evaluation criteria and reporting guidelines were found that were applicable to quantitative medical education research. Whereas some of these tools are quite broad, ${ }^{13}$ covering quantitative research in general, others are extremely specific, outlining specifically how to report quantitative medical education research using a specific methodology. ${ }^{16}$ Because these guidelines outline the criteria for identifying and producing high-quality research, they should serve as a starting point for junior medical education scholars who are designing quantitative studies. We anticipate that these scholars will know what type of quantitative research that they are conducting and quickly identify the most relevant tools for their work using Table 2 .

Although this work is likely to provide a helpful starting point for junior researchers, the complexity of medical education research is such that no advice or sets of guidelines can replace formal training in research methodologies nor advice from experts in the field., ${ }^{6,24}$ Indeed, as the depth and scope of quantitative research in medical education continue to grow, increasing amounts of expertise and/or collaboration with skilled partners will be needed to produce high-quality, publication-worthy scholarship. ${ }^{24}$

\section{LIMITATIONS}

Although our literature review returned a reasonable number of articles for review, the restrictiveness of the 
Table 2. Summary of reporting guidelines and quality assessment tools relevant to quantitative medical education research

Best Evidence in Medical Education (BEME) Global rating ${ }^{14}$

Recommendations for reporting

Mastery Education Research in

Medicine (ReMERM) guidelines ${ }^{16}$

STROBE (strengthening the reporting

of observational studies in

epidemiology $)^{17}$

$B M J$ guidelines ${ }^{18}$

Cook Key elements of reporting ${ }^{19}$

CONSORT guidelines for non-

pharmacologic interventions ${ }^{20}$

TiDieR guidelines ${ }^{21}$

SQUIRE guidelines

EQUATOR

GREET $^{22}$
Specific to medical education

Hypothesis-testing investigations and measurements of

educational interventions in quantitative research

Experimental, quasi-experimental, observational studies

Intervention evaluation studies involving non-randomized designs

Non-randomized studies included in systematic reviews

Non-randomized studies

For mastery learning research studies in medical education

Analytical observational studies (cohort, case-control, and cross-sectional studies)

Studies on educational interventions

Experimental studies (including single group, posttest only studies, static group comparisons, and non-randomized and randomized trials, and evaluation studies with experimental designs)

Randomized controlled trials (with focus on individually randomized, two group, parallel trials

An expansion of CONSORT, applies to experimental studies, observational studies, study protocols, systematic reviews/

meta-analyses/Health Technology Assessment

Quality improvement studies

a list of what authors should write and publish for various

types of studies

Education interventions

research?

Yes

Reporting guideline or quality assessment tool?

Quality assessment tool designed to evaluate the most important medical education articles published each

year

Quality assessment tool designed to evaluate the methodological quality

No (developed for behavioural and public health intervention studies)

guideline for authors and journal reviewers

No (developed for clinical

A risk of bias quality assessment tool research and modified for systematic reviews of MedEd research)

Yes, a modified version of

Kirkpatrick's hierarchy ${ }^{15}$

Yes

Quality assessment tool

Reporting guideline to assist educators, authors, peer reviewers, journal editors, and readers

Recommendations and guidance for the reporting of observational research

Reporting guidelines for authors, reviewers, editors, and readers

Reporting guideline

Reporting guideline

Reporting guideline

Reporting guideline

A network that provides reporting

guidelines for a wide variety of fields

Reporting guideline

EM Score = Academic Emergency Medicine Score, MERSQI = Medical Education Research Study Quality Index 
search could be criticized. We believe that the databases and search terms that were selected were appropriate for the topic of interest and, given that medical education research has advanced substantially in the past decade, restricting the review to articles published within the last 10 years allowed more modern and applicable lists of recommendations and reporting guidelines to be identified. However, in limiting the search to the English language, we likely missed literature that could have added to our findings.

\section{CONCLUSION}

In this paper, we attempted to provide guidance for junior researchers and authors in the form of key recommendations and reporting guidelines. We achieved this through a scoping review of the literature and thematic analysis, with a focus on quantitative educational research and scholarship. We believe that these results will assist junior researchers who heed the recommendations and guide them to key tools for their type of research.

Competing interests: None declared.

\section{REFERENCES}

1. Bandiera G, LeBlanc C, Regehr G, et al. Education scholarship in emergency medicine part 2: supporting and developing scholars. CFEM 2014;15(S1):S6-12, doi: doi: $10.2310 / 8000.2014 .141455$.

2. Sherbino J, van Melle E, Bandiera G, et al. Education scholarship in emergency medicine part 1 : innovating and improving teaching and learning. CFEM 2014;15(S1):S1-5, doi: $10.2310 / 8000.2014 .141454$.

3. Bhanji F, Cheng A, Frank JR, et al. Education scholarship in emergency medicine part 3: a "how-to" guide. CFEM 2014;16(Suppl 1):S13-8.

4. Gordon JA. Reflections on the consensus process: a leadership role for emergency medicine in educational scholarship and practice across health care. Acad Emerg Med 2012;19(12):1333-5, doi:10.1111/acem.12020.

5. Sinclair D, Worthington JR, Joubert G, et al. CAEP 2015 Academic Symposium: leadership within the emergency medicine academic community and beyond. CFEM 2016; 18(S1):S1-9, doi:10.1017/cem.2016.9.

6. Perry JJ, Snider EC, Artz DJ, et al. CAEP 2014 Academic Symposium: how to make research succeed in your emergency department: how to develop and train career researchers in emergency medicine. CFEM 2015;17(3): 334-43, doi:10.1017/cem.2015.63.

7. Schuwirth LWT, van der Vleuten CPM. Medical education: challenges for educationalists. BM7 2006;333:544-6.
8. Arksey H, O'Malley L. Scoping studies: towards a methodological framework. Int 7 Soc Res Methodol 2005;8(1):19-32, doi:10.1080/1364557032000119616.

9. Beckman TJ, Cook DA. Developing scholarly projects in education: a primer for medical teachers. Med Teach 2007; 29(2-3):210-8.

10. Farrell SE, Kuhn GJ, Coates WC, et al. Critical appraisal of emergency medicine education research: the best publications of 2013. Acad Emerg Med 2014;21(11):1274-83.

11. Reed DA, Beckman TJ, Wright SM, et al. Predictive validity evidence for medical education research study quality instrument scores: quality of submissions to JGIM's Medical Education Special Issue. 7 Gen Intern Med 2008;23(7):903-7.

12. Jarlais D, Don C. Improving the reporting quality of nonrandomized evaluations of behaviorial and public health interventions: the TREND statement. Am 7 Public Health 2004;94(3):361-6, doi:10.1111/j.1360-0443.2004.00785.x.

13. Lo CK-L, Mertz D, Loeb M. Newcastle-Ottawa Scale: comparing reviewers' to authors' assessments. BMC Med Res Methodol 2014;14(45):1-5, doi:10.1186/1471-228814-45.

14. Sullivan GM. Deconstructing quality in education research. 7 Grad Med Educ 2011;3(2):121-4, doi:10.4300/JGME-D11-00083.1.

15. Kirkpatrick DL. Evaluating training programs, 3rd ed. San Francisco: Berrett-Koehler; 1994.

16. Cohen ER, Mcgaghie WC, Wayne DB, et al. Recommendations for Reporting Mastery Education Research in Medicine (ReMERM). Acad Med 2015;90(11):1-6, doi:10.1097/ ACM.0000000000000933.

17. von Elm E, Altman DG, Egger M, et al. The strengthening the reporting of observational studies in epidemiology (STROBE) statement: guidelines for reporting observational studies. Int 7 Surg 2014;12(12):1495-9, doi:10.1016/ j.ijsu.2014.07.013.

18. Education Group for Guidelines on Evaluation. Guidelines for evaluating papers on educational interventions. BM7 1999;318(7193):1265-7.

19. Cook DA, Beckman TJ, Bordage G. Quality of reporting of experimental studies in medical education: a systematic review. Med Educ 2007;41(8):737-45.

20. Schulz KF, Altman DG, Moher D. CONSORT 2010 Statement: updated guidelines for reporting parallel group randomised trials. BMC Med 2010;340:c322.

21. Hoffmann TC, Glasziou PP, Boutron I, et al. Better reporting of interventions: template for intervention description and replication (TIDieR) checklist and guide. BM7 2014;348:g1687, doi:10.1136/bmj.g1687.

22. Phillips AC, Lewis LK, McEvoy MP, et al. A Delphi survey to determine how educational interventions for evidencebased practice should be reported: stage 2 of the development of a reporting guideline. BMC Med Educ 2014; 14(1):159, doi:10.1186/1472-6920-14-159.

23. Hsu C, Sandford B. The Delphi technique: making sense of consensus. Pract Assessment Res Eval 2007;12(10):1-8, doi:10.1016/S0169-2070(99)00018-7.

24. Sherbino J. Education scholarship and its impact on emergency medicine education. West 7 Emerg Med 2015; 16(6):804-9, doi:10.5811/westjem.2015.9.27355. 